\section{Ectopic Pancreas Presenting as a Large Gastric Antral Papilla}

Ectopic pancreatic tissue localized in the distal stomach rarely presents symptoms unless it is complicated by bleeding or mucosal ulceration. The appearance on endoscopic ultrasound (EUS) examination is characterized by an indistinct margin, a heterogeneous appearance, and location within either the third or the fourth echo layer [1]. Thickening of the fourth echo layer (muscular hypertrophy) has commonly been seen.

A 67-year-old woman was admitted in order to undergo polypectomy of a gastric lesion (Figure 1a). There was no history of abdominal pain, dyspepsia, or signs of bleeding or ulceration. Serum pancreatic enzyme levels were normal.
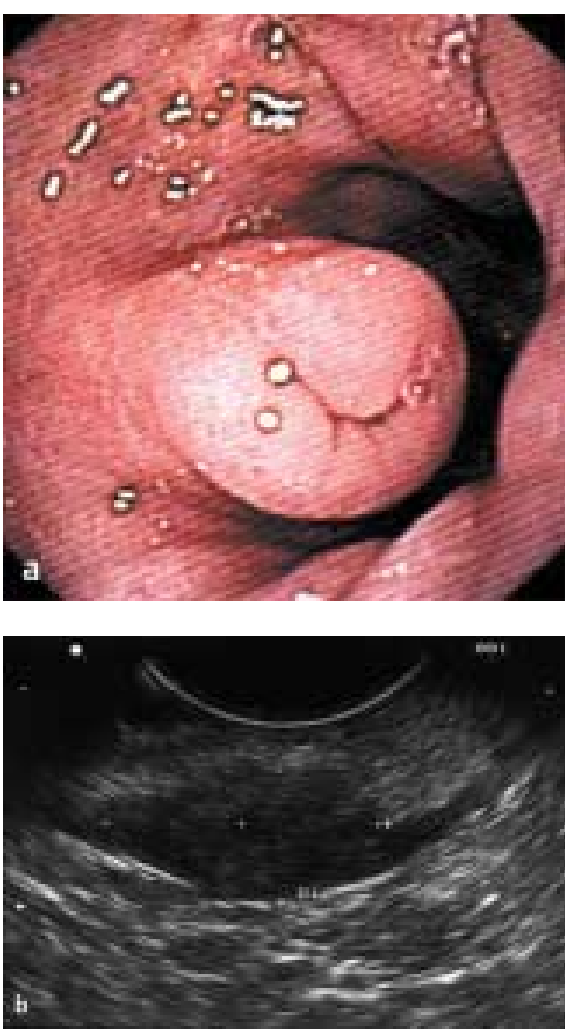

Figure 1 a Gastroscopic view of the papillalike lesion in the antrum. b Endoscopic ultrasound (EUS) examination demonstrated a heterogeneous appearance and location within either the third or the fourth echo layer.
Work-up, which included upper gastrointestinal endoscopic and EUS examination, revealed a lesion exhibiting a characteristic central umbilication and intramural mass on the front wall of the antrum with a diameter of $20 \mathrm{~mm}$ [2] (Figure $\mathbf{1} \mathbf{b}$ ). The lesion looked like a papilla, but it was impossible to insert a catheter. No single endosonographic criterion could be obtained that would enable accurate differentiation between benign and malignant submucosal tumors of the upper gastrointestinal tract [3].

Most patients with ectopic pancreas are asymptomatic, but nonspecific gastrointestinal symptoms associated with pancreatitis, cyst formation, jaundice, abscess formation, gastric outlet obstruction, and malignant change have been described [4]. Endoscopic biopsy specimens obtained with a standard forceps are often nondiagnostic because the structures that characterize ectopic pancreas are situated below the mucosa.

The patient underwent endoscopic polypectomy, and histologic examination in the submucosa showed dilated cystic ducts with cubic epithelium, fibrosis, and an island of pancreatic tissue (the investigation was performed by Prof. Dr Loy of the Pathological Institute) (Figure 2). The lesion did not present with disabling symptoms and we think that surgical excision or endoscopic resection should not be performed if the diagnosis is known [5].

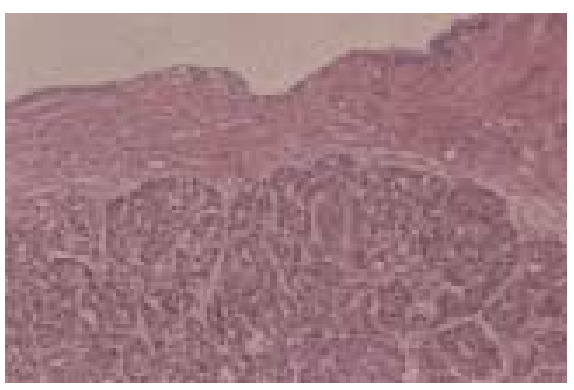

Figure 2 Photomicrograph of the ectopic pancreatic tissue.

\section{U. Gottschalk, B. Casper, G. Boden}

Klinik für Innere Medizin -

Gastroenterologie,

Klinikum Prenzlauer Berg,

Berlin, Germany

\section{References}

${ }^{1}$ Matsushita M, Hajiro K, Okazaki K, Takakuwa H. Gastric aberrant pancreas: EUS analysis in comparison with the histology. Gastrointest Endosc 1999; 49: $493-497$

2 Pouessel G, Michaud L, Pierre MH et al. Endoscopic diagnosis of a gastric heterotopic pancreas and esophageal atresia: an incidental association? Arch Pediatr 2001; 8: 181 - 185

${ }^{3}$ Rösch T, Lorenz R, Dancygier H et al. Endosonographic diagnosis of submucosal upper gastrointestinal tract tumors. Scand J Gastroenterol 1992; 27: 1 -8

${ }^{4}$ Sloots CE, de Brauw LM, Bot FJ, Greve JW. False-positive cytology in diagnostic laparoscopy due to ectopic pancreas. Dig Surg 1999; 16: 434-436

${ }^{5}$ De Friend DJ, Saa-Gandi FW, Humphrey CS, Foster DN. Symptomatic pancreatic heterotopia treated by local excision. Gut 1991; 32: $332-333$

\section{Corresponding Author}

\section{U. Gottschalk, M.D.}

Klinik für Innere Medizin

- Gastroenterologie

Klinikum Prenzlauer Berg

Föbelstrasse 15

10405 Berlin

Germany

Fax: + 49-30-42421098

E-mail: uwe.gottschalk@kpb-berlin.de 